\title{
Sphenoid Sinus
}

National Cancer Institute

\section{Source}

National Cancer Institute. Sphenoid Sinus. NCI Thesaurus. Code C12278.

Either of the paired paranasal sinuses, located in the anterior part of the body of the sphenoid bone and communicating with the superior meatus of the nasal cavity on the same side. 